thành phần của khối thoát vị rất phong phú, kết quả chụp $\mathrm{CHT}$ có thể giúp bác sỹ phẫu thuật tiên lượng cuộc mổ và có kế hoạch bóc tách các dây chằng, rễ thần kinh và u mõ tốt nhất.

Tình trạng tủy bám thấp trong nghiên cứu của chúng tôi chiếm $96,9 \%$, kết quả này cũng tương đồng với Dư Văn Nam là $96,5 \%$, Mark S. Greenberg là $98 \%$ [8], [9]. Trong bệnh lý TVTMT do chóp tủy và chùm đuôi ngựa bị dính chặt vào khối thoát vị, ngăn cản sự đi lên của tủy trong quá trình phát triển, nên hầu hết bệnh nhân đều có tủy bám thấp. Tuỷ bám thấp làm cản trở sự phát triển của tuỷ và làm căng các rễ thần kinh nên trẻ càng lớn thì các triệu chứng thần kinh (hội chứng tuỷ) càng bộc lộ rỗ. Do đó phẫu thuật viền phải có kế hoạch phẫu thuật giải phóng tuỷ và tạo hình tuỷ sônng sớm ở các bệnh nhân này.

\section{KẾT LUẬN}

TVMNT vùng cùng cụt ở trẻ em là bệnh lý hiếm gặp, được chẩn đoán xác định bằng chụp $\mathrm{CHT}$ cột sống. Phương pháp này có vai trò quan trọng trong việc xác định vị trí, kích thước và thành phần của khối thoát vị giúp cho chẩn đoán chính xác, tiên lượng và lập kế hoạch điều trị tốt nhất.

\section{TÀI LIÊU THAM KHẢO}

1. Marks JD, Khoshnood B. Epidemiology of common neurosurgical diseases in the neonate. Neurosurgery clinics of North America. 1998; 9(1): 63-72.

2. Brea CM, Munakomi S. Spina Bifida, StatPearls Publishing. 2021; StatPearls Publishing LLC., Treasure Island (FL).

3. Alruwaili AA, J MD(2021). Myelomeningocele, StatPearls Publishing Copyright (C) 2021, StatPearls Publishing LLC., Treasure Island (FL).

4. Lorber J. Results of treatment of myelomeningocele. An analysis of 524 unselected cases, with special reference to possible selection for treatment. Developmental medicine and child neurology. $1971 ; 13(3): 279-303$.

5. Phạm Hồng Huân. Nghiên cứu điều tri thoát vị tủy - màng tủy vùng thắt lưng - cùng ở trẻ em. Luân văn Thac sĩ Y hoc. Đai Hoc Y Dước Thành Phố Hồ Chí Minh, Thành phố Hồ Chí Minh. 2006.

6. Trân Quang Vinh. Ứng dung của phương pháp kích thích thân kinh cơ trong phâuu thuật thoát $\mathrm{V}$ tủy màng tủy. Y Học TP Hồ Chí Minh 2012; 16(4): 247-252.

7. Özek MM. Spina bifida: management and outcome. Springer. 2008; 30(3): 49 - 59.

8. Dư Văn Nam. Đăc điểm lâm sàng, chẩn đoán hình ảnh và kết quả điều trị vi phẫu thoát vị tủy - màng tủy. Luân văn Thac sĩ Y học, Đai Học Y Hà Nội. 2020.

9. Greenberg MŚ. Handbook of Neurosurgery Thieme New York. 2006; 7(6): 350 - 400.

\title{
MÔTT TRƯờNG HỢP HIẾM GĂP: THAI TRONG Ổ BỤNG Ở MẠC TREO ĐẠI TRÀNG GÓC GAN
}

\author{
Trưong Thanh Thanh*, Trịnh Thanh Nhung*, \\ Phạm Đặng Tấn Hưng*, Hồ Trung Nghĩa*, Châu Hữu Hầu*
}

\section{TÓM TẮT}

Đối tương: Thai phu 28 tuổi, PARA 1001, đăt vòng tránh thai 10 năm, đang điều trị hội chứng thẩn hư 2 năm; vào viên vì đau bung, mất máu cấp, siểu âm dịch ố bụng nhiều, không thấy túi thai. Test thai (+), beta hCG $1447 \mathrm{mIU} / \mathrm{ml}$. Chẩn đoán: Thai ngoài tử cung vỡ/Hội chứng thận hư đang điều trị. Xử trí: Phẫu thuât mở theo đường Pfannestiel. Loa vòi phải hơi to có điểm xuất huyết nhỏ không chảy máu, có nhiều máu cục trên gan, lây ra 300 gram máu cục. Kiểm tra ổ bụng không thấy bất thường. Dấn lưu, đóng bung 3 lớp. Sau 10 giờ hậu phẫu, bệnh nhân lại có dấu hiện mất máu cấp, siêu âm: máu ổ bụng lượng vừa. Quyết định nội soi thám sát, thây nhau làm tổ ở mạc treo đại tràng góc gan đang chảy máu, kẹp đốt

*Bệnh viện Nhật Tân

Chịu trách nhiệm chính: Châu Hữu Hầu

Email: benhviennhattan@gmail.com

Ngày nhận bài: 7.9.2021

Ngày phản biên khoa họ: 28.10.2021

Ngày duyệt bài: 9.11.2021 cầm máu và khâu lại, Hậu phẫu: bệnh ổn định. Kết luận: Một trường hợp hiếm gặp: thai trong ổ bụng ở mạc treo đại tràng góc gan. Có thể rút ra một sổ kinh nghiệm sau: 1.Khi đã xác định thai ngoài tử cung, cố gắng xác định vị trí làm tổ cửa nhau thai. 2.Cân nhắc điêu trị methotrexate hay phấu thuật hoặc phối hợp cả hai. 3.Ưu tiên chọn mổ nội soi hơn mổ mở. 4.Nếu mổ mở, nên mổ dọc để rộng phẫu trường, khi cần. 5.Các bác sĩ sản phụ khoa và bác sĩ ngoại khoa nên hiểu rõ tính phức tạp của thai ngoài tử cung để có thể phối hợp giải quyết.

Tư khóa: Thai ngoài tử cung (TNTC), thai trong ổ bụng (TTOB)

\section{SUMMARY}

A RARE CASE: INTRA-ABDOMINAL PREGNANCY IN THE MESOCOLIC FLEXURE OF THE LIVER

28-year-old pregnant woman, PARA 1001, 10 years of IUD insertion, 2 years of treatment for nephrotic syndrome. Admitted to the hospital because of abdominal pain, acute blood loss. US finding: a lot of abdominal fluid, no gestational sac. Positive 
pregnancy test, beta hCG $1447 \mathrm{mIU} / \mathrm{ml}$. Diagnosis: Ruptured ectopic pregnancy/Nephrotic syndrome being treated. Treatment: Open surgery with Pfannestiel incision: Right fimbriae must be slightly enlarged with small bleeding points without bleeding, there were many blood clots on the liver, 300 grams of blood clots were removed. Exploring the abdominal cavity wasn't abnormal. Drained and closed the abdomen in 3 layers. After 10 hours of surgery, the patient continued to show signs of acute blood loss, abdominal US finding had moderate free blood. Decided to have laparoscopic surgery to see that the placenta implanted in the mesocolic flexure of the liver was bleeding. We burned and clamped it to stop the bleeding here and sutured the abdomen. Postoperatively, the patient was fine. Conclusion: We draw some experiences as follows: 1 . Once the ectopic pregnancy has been identified, try to determine the location of the placenta's implantation. 2. Consider methotrexate or surgery, or a combination of both. 3 . Prioritize choosing endoscopic surgery over open surgery. 4. If open surgery, should be operated longitudinally to widen the surgical field, when needed. 5. Obstetrician-Gynecologists and general surgeons should understand the complexities of ectopic pregnancy so that they can sometimes work together to manage them.

Keywords: Ectopic pregnancy, abdominal pregnancy.

\section{I. ĐẶT VẤN ĐỀ}

Thai ngoài tử cung (TNTC) là trường hợp thai nằm ngoài buồng tử cung. Thai ngoài tử cung phần lớn xảy ra ở khoảng kẽ $(2,4 \%)$, eo $(12,0 \%)$, bóng $(70,0 \%)$, loa vòi $(11,1 \%)$, buồng trứng $(3,2 \%)$ hoặc ổ bụng $(1,3 \%)$. Nhưng các vị trí khác có thể xảy ra bao gồm cổ tử cung, sẹo tử cung do mổ lấy thai, trong thành tử cung... Trong một số trường hợp hiếm gặp, đa thai có thể là lạc chố (heterotopic), bao gồm cả thai trong tứ cung và thai ngoài tử cung [1].

Thai trong ổ bụng (TTOB) đã được định nghĩa là thai thanh mạc xảy ra trong khoang phúc mac nhưng loại trừ những thai ngoài ở ống dẩn trứng, buồng trứng, hoặc do hậu quả của việc cây ghép ống dẫn trứng. Các tiêu chí được sử dụng để chẩn đoán TTOB được Studdiford mô tả vào năm 1944 như sau: (1) Vòi trứng và buồng trứng bình thường, (2) Không có bằng chứng về lỗ rò phúc mạc tữ cung, (3) Thai nghén chỉ liên quan đến bề mặt phúc mạc, và (4) Không có bằng chứng về sự cấy ghép thứ phát xảy ra sau khi làm tổ trong ổng dẫn trứng [2].

Nhiều tranh luận về TTOB là thứ phát do thai từ buồng trứng hoặc vòi trứng võ vào ổ bụng. Nằm 1962, Beacham và cs cho rằng TTOB nguyên phát có thể xảy ra nhưng rất hiếm gặp. Jeffcoate, năm 1967 và Johnson năm 1968 cũng thống nhất cho rằng trong khi đa số TTOB là thứ phát nhưng có một ít nguyên phát có thể đã xảy ra [3].

Các trường hợp TTOB rất hiếm gặp và đã có trong một số báo cáo 1 ca. Năm 2012, Poole và cs đã nghiên cứu trên y văn từ năm 1965 đến tháng 8 năm 2009 về các trường hợp TTOB đã chọn ra 225 trường hợp ТТОВ trong số 511 trường hợp TNTC [2].

Nối tiếp công trình của Poole và cs là công trình của Eisner và cs dựa trên phân tích có hệ thống các báo cáo trường hợp trên các cơ sở dữ liệu PubMed, Livivo và Google Scholar trong giai đoạn 2007 đến 2019 về các trường hợp mà ông gọi là TNTC hiếm gặp. Qua công trình này, tần suất TNTC được ước tính là 11 trường hợp trên 1000 ca mang thai, chiếm tỷ lệ $1,1 \%$. Và các trường hợp TTOB càng hiếm gặp hơn, chỉ chiếm $1,3 \%$ TNTC [4]. Atrash và cs ước tính có 10,9 ca mang thai trong bụng trên 100.000 ca đẻ sống [5].

Trong số các trường hợp TTOB thì thai nằm ở mạc treo ruột càng hiếm. TTOB ở mạc treo đại tràng góc gan lại càng hiếm hơn, bằng chứng là trong 115 trường hợp mà Eisner đã tập hợp trong 12 năm chỉ có $9(7,8 \%)$ TTOB ở treo ruột, nhưng không rõ vị trí trong ổ bụng [4]. TTOB được báo cáo có nguy cơ tử vong me cao gấp 78 lần so với TNTC. Các yếu tố nguy cơ của TTOB bao gồm tiền sử TNTC, nhiễm trùng vùng chậu nhỏ, mang thai bằng kỹ thuật hô̂ trợ sinh sản và hút thuốc lá [4].

Nghiên cứu này nhằm mô tả một trường hợp TTOB hiếm gặp, nằm ở mạc treo đại tràng góc gan, nhằm chia sẻ kết quả trải nghiệm và một vài kinh nghiệm thực tế của chúng tôi.

\section{BỆNH ÁN TRƯỜNG HợP}

Bệnh sử: Bệnh nhân nữ 28 tuổi, kinh nguyệt không đều. Trước khi nhập viện 17 giờ bệnh nhân đau bụng vùng hạ sườn phải, tự mua thuốc giảm đau uống không giảm, đau bụng âm ỉ liên tục, đau tăng dần khắp bụng, xin nhập viện. Tình trạng lúc vào viện: Bệnh nhân tỉnh; niểm hồng nhạt; HA $101 / 73 \mathrm{mmHg}$; mạch 78 lần/phút; nhiệt độ 37 độ C; nhịp thở 21 lần/phút. Tim nhịp đều; phổi trong; bụng chướng nhẹ, ấn đau khẳp bụng, phản ứng thành bụng $(+)$. Khám âm đạo: Cổ tử cung láng, lắc cổ tử cung đau; thân tử cung hơi to, 2 phần phụ khó xác định; túi cùng sau phồng, ấn đau; âm đạo ra ít huyết sậm. Tiền sử: PARA 1001 (sanh thường năm 2010), đặt vòng $T$ tránh thai 10 năm nay. Đang điều trị hội chứng thận hư 2 năm với methylprednisolone 1 viên uống/ngày và aziathioprine (Imurel) $50 \mathrm{mg} 2$ viên uống/ngày. 
Chưa ghi nhận bệnh lý khác và dị ứng thuốc. Cận lâm sàng: Siêu âm bụng: dịch ổ bụng $(++)$ lợn cợn cản âm nghĩ máu, khồng thấy túi thai. Test thai $(+)$. Xét nghiệm máu: Beta hCG $1.447 \mathrm{mIU} / \mathrm{ml}$, RBC: $3 ., 44106 / \mathrm{mm}^{3}$; HGB: 8,0 g/dl; Hct: 26,1 \%; creatinin: 49 micromol/l; urê : $3,7 \mathrm{mmol} / \mathrm{l}$. Chẩn đoán: Thai ngoài tử cung vỡ/Hội chứng thận hư đang điều trị. Xử trí: Cấp cứu tuần hoàn, truyền máu khẩn. Phẫu thuật cấp cứu 1 giờ sau nhập viện. Phương pháp vô cảm: Mê nội khí quản. Phương pháp phẫu thuật: Mổ mở.

Tường trình phẫu thuật lần 1: Rach da đường ngang (Pfannestiel) trên khớp vệ. Vào ổ bụng hút khoảng $500 \mathrm{ml}$ máu loãng. Thám sát thây loa vòi trứng phải hơi to có điểm xuất huyết nhỏ không chảy máu, buồng trứng phải hơi to không chảy máu. Vòi trứng và buồng trứng trái bình thường. Thám sát mặt trước, mặt sau tử cung và túi cùng Douglas không thấy tổn thương. Kiểm tra thấy nhiêu máu cục trên gan, lấy 300 gram máu cục trên gan. Kiểm tra gan, lách, dạ dày và các bộ phận khác trong ổ bụng không thây điểm xuất huyết và không tổn thương. Dẩn lưu Douglas. Đóng bụng 03 lớp. Máu mất \# 900ml. Chẩn đoán sau phâuu thuật: Thai ngoài tử cung ở vòi trứng phải sẩy qua loa + Hội chứng thận hư đang điều trị.

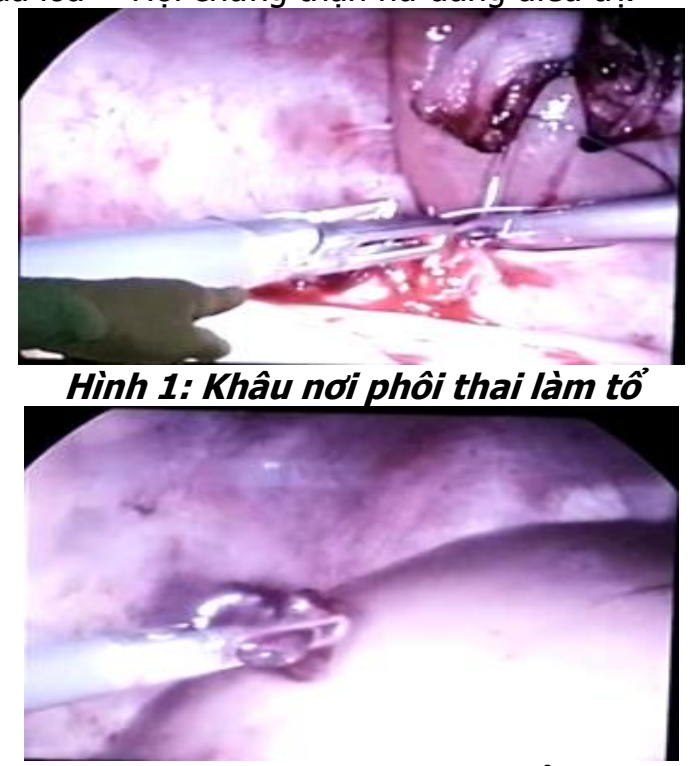

Hình 2: Lấy phôi thai khỏi ố bung

Diễn tiến sau phẫu thuật lân 1: (1) Hậu phẫu 6 giờ đâu tại khoa GMHS: Đã truyền 2 đơn vị máu. Bệnh nhân tỉnh, niêm hồng hơn, sinh hiệu ổn; tim đều; phổi trong, bụng mềm. Vết mố khô, không dịch thấm băng thêm. Dẫn lưu Douglas ra \# $22 \mathrm{ml}$ dịch hồng lợt. Nước tiểu qua thông vàng trong.
(2) Hậu phẫu giờ thứ 9: Bệnh nhân tỉnh, niêm nhạt. Mạch: 89 lần/ phút, HA $108 / 71 \mathrm{mmHg}$, nhiệt độ $37^{\circ} \mathrm{C}$; nhịp thở 19 lần/phút; nhịp tim đều; phổi trong. Bụng chướng; đau khắp bụng. Vết mổ khô, không dịch thấm băng. Dẫn lưu Douglas ra $10 \mathrm{ml}$ dịch hồng lợt. Nước tiểu qua sonde vàng sậm $150 \mathrm{ml} / 2$ giờ 40 phút. Xử trí: Xét nghiệm công thức máu, dự trù 2 đơn vị máu cùng nhóm. Siêu âm tại giường. Siêu âm bụng: Bệnh nhân đau nhiều vùng hạ sườn phải; dày thành túi mật; dịch ổ bụng $(++)$ lợn cợn có cản âm nghĩ máu. Hct 19,4\%, hemoglobin 6,0g/dl. Chẩn đoán: Thai ngoài tử cung chưa rõ vị trí, nghĩ nhiều đến thai trong ổ bụng. Hội chẩn quyết định: Nội soi thám sát cầm máu và chẩn đoán.

Phấu thuật lân 2: Mổ nội soi, vào ổ bụng với 3 trocar. Quan sát thấy tử cung và hai phần phụ không chảy máu, có nhiều máu cục và máu loãng sậm trong ổ bụng và dưới gan, tiến hành hút sạch máu cục và loãng, thám sát thấy khối thai ngoài dính chặt vào mạc treo ở đại tràng góc gan. Gõ khối nhau thai, tổn thương đang chảy máu rỉ rả, kẹp đốt điểm cầm máu và khâu tổn thương, lấy khối thai gửi giải phẫu bệnh lý. Dẫn lưu Douglas và dưới gan, máu mất khoảng $700 \mathrm{ml}$, Chẩn đoán hậu phẫu: Thai ngoài tử cung vỡ ở mạc treo ruột vùng đại tràng góc gan.

Kết quả sau 4 ngày phấu thuật lần 2: Hct 33.9, beta-HCG $39.3 \mathrm{mIU} / \mathrm{ml}$ (<7 mIU/ml). Bệnh nhân ổn định dần, ra viện sau 01 tuần điều trị. Tái khám sau 3 tuần xuất viện: beta-HCG 5.6 $\mathrm{mIU} / \mathrm{ml}(<7 \mathrm{mIU} / \mathrm{ml})$.

\section{BÀN LUÂ̂N}

Trường hợp TTOB ở mạc treo đại tràng góc gan khá hiếm gặp trên y vắn ở một thai phụ còn đang đặt vòng tránh thai và đang điều trị hội chứng thận hư 2 năm nay. Khó hơn nữa khi siêu âm không thây phôi thai ngoài tử cung ở vị trí thường gặp. Việc mổ mở đường ngang dẫn đến hạn chế nhất định trong thám sát ổ bụng. Thực tể cho thây không phải phẫu thuật viên nào cũng gặp trường hợp TTOB trong thời gian hành nghề nển ít nhiêu thiếu kinh nghiệm, dẫn đến thiếu sót trong xử lý.

Do TTOB nhất là ở mạc treo đại tràng góc gan rất hiếm gặp. Tìm trên y văn, chúng tôi gặp một báo cáo của Trail và cs [6] vào nằm 2018 về một trường hợp TNTC ở góc gan với các dấu hiệu nghĩ đến TNTC và $\beta H C G$ huyết thanh tăng. Siểu âm qua âm đạo: tử cung trống, không có túi thai và có dịch $7 \mathrm{~mm}$ trong lòng tứ cung; có một khối không đồng nhất $31 \times 21$ mm tiếp giáp với 
buồng trứng phải. Một lượng dịch vừa phải ở cả hai phần phụ. Khi nội soi ổ bụng, máu trong phúc mạc khoảng $500 \mathrm{ml}$, cả hai ống dẫn trứng và buồng trứng đều bình thường. Khi kiểm tra khoang bụng thấy một thai ngoài tử cung ở góc gan; không thấy chảy máu, rửa vùng chậu mà không can thiệp phẫu thuật. Ngày hôm sau, $\beta$ HCG huyết thanh giảm còn $872 \mathrm{IU} / \mathrm{mL}$. Bệnh nhân được tư vấn về những phát hiện khi nội soi và xử trí methotrexate 2 lân, cách nhau 1 tuần, theo dõi điều trị ngoại trú. Ngày $28, \beta H C G$ huyêt thanh còn $13 \mathrm{IU} / \mathrm{mL}$ và bệnh nhân được xuất viện [6].

Trường hợp của bệnh viện chúng tôi cho thấy đây một thai phụ 28 tuổi, PARA 1001, một lần sanh thường, đặt vòng đã 10 năm, đang uống điều trị hội chứng thận hư 2 năm nay với methylprednisolone $16 \mathrm{mg} 1$ viên uống/ngày và aziathioprine (Imurel) $50 \mathrm{mg} 2$ viên uống/ngày. Chúng tôi cho rằng đây là một ca bệnh rất hiếm gặp và có thể cho chúng tôi nhiều bài học bổ ích. Trong $\mathrm{y}$ văn, chúng tôi chưa tìm thấy bằng chứng về mối liên hệ giữa TNTC và các thuốc điều trị hội chứng thận hư.

Ngoài ra, vai trò của bác sĩ ngoại tổng quát ở trường hợp này khá quan trọng, có thể hỗ trợ các bác sĩ phụ sản trong việc thám sát và xử trí các thương tổn khác trong ổ bụng sản phụ.

\section{KẾT LUẬN}

Đây là một trường hợp hiếm gặp, có thai ở mạc treo đại tràng góc gan trên một phụ nữ 28 tuổi, còn vòng $T$ trong lòng tử cung và đang điều trị hội chứng thận hư. Qua trường hợp này có thể rút ra một số kinh nghiệm như sau: 1 . Khi đã xác định thai ngoài tử cung, cố gắng xác định vị trí làm tổ của nhau thai. 2. Cân nhắc điều trị methotrexate hay phẫu thuật hoặc phối hợp cả 2. 3. Uuu tiên chọ mổ nôi soi hơn mổ mở. 4. Nếu mổ mở, nên mổ dọc để rộng phẫu trường, khi cần. 5 . Các bác sĩ sản phụ khoa và bác sĩ ngoại khoa nên hiểu rõ tính phức tạp của thai ngoài tử cung để có thể phối hợp cùng giải quyết, tránh tai biến đáng tiếc.

\section{TÀl LIỆU THAM KHẢO}

1. Bouyer J, Coste J, Fernandez H, Pouly JL, Job-Spira N. Sites of ectopic pregnancy: a 10 year population-based study of 1800 cases. Hum Reprod. 2002;17(12):3224.

2. Poole A, Haas D, Magann EF. Early Abdominal Ectopic Pregnancies: A Systematic Review of the Literature. Gynecol Obstet Invest 2012;74:249-260.

3. Johnson AG. Primary Peritoneal Pregnancy. Bri. Med,. 1968, 4, 96-97.

4. Eisner SM, Ebert AD, David M. Rare Ectopic Pregnancies - A Literature Review for the Period 2007 - 2019 on Locations Outside the Uterus and Fallopian Tubes. Geburtshilfe Frauenheilkd. 2020 Jul; 80(7): 686-701.

5. Atrash HK, Friede A, Hogue CJ. Abdominal pregnancy in the United States: frequency and maternal mortality. Obstet Gynecol. 1987 Mar;69(3 Pt 1): 333-7.

6. Trail CE, Watson A, Schofield AM. Case of hepatic flexure ectopic pregnancy medically managed with methotrexate. BM] Case Rep. 2018; 2018: bcr2017220480. Published online 2018 Mar 17.

7. Yasutake N. Tsunematsu R. Oishi H. Yahata H. Uchida S. Kobayashi H. Kato K. Successfully Treated Abdominal Pregnancy Causing Hemoperitoneum Using Combined Surgical and Systemic Methotrexate Therapy: A Case Report and Review of Cases Treated at Kyushu University Hospital. 2013, Vol.76, No.3.

\section{ĐÁNH GIÁ KẾT QUẢ HÓA XA TRI TIỀN PHẪU UNG THƯ TRỰC TRÀNG BẰNG KĨ THUÂ̂T VMAT KẾT HợP CAPECITABINE ĐƯờNG UỐNG TẠI BỆNH VIỆN K}

\section{TÓM TẮT}

Mục tiêu: Nhận xét một số đặc điểm lâm sàng, cận lâm sàng bệnh nhân Ung thư trực tràng tại Bệnh viện $\mathrm{K}$ từ 06/2018 đến 10/2021. Đánh giá kết quả hóa

\section{*Bênh Viên $K$}

Chiu trách nhiệm chính: Phạm Khánh Toàn

Email: pktoanvk@gmail.com

Ngày nhận bài: 6.9.2021

Ngày phản biện khoa học: 25.10.2021

Ngày duyệt bài: 8.11.2021
Phạm Khánh Toàn', Võ Văn Xuân ${ }^{1}$

xạ trị trước mổ ung thư trực tràng bằng kỹ thuât điều biến liều thể tích hình cung (VMAT) kết hợp Capecitabin đường uống. Đối tượng và phương pháp nghiên cứu: Nghiên cứu cạn thiệp lâm sàng không đối chứng, cỡ mẫu thuận tiện. Kểt quả: Tuổi trung bình 58,6 tuổi. Tuổi thường gặp từ $51-70$ chiếm $76,6 \%$. Tỉ lệ nam/nữ : 1,4. Thới gian phát hiện bệnh $\leq 6$ tháng chiếm $84,9 \%$. Triệu chứng hay gặp trong UTTT gồm đi ngoài phân lẫn máu $87,2 \%$. Khối u di đông một phần chiếm $65,5 \%$. Ung thư biểu mô tuyến chiếm $100 \%$, thể nhầy chiếm $14,8 \%$. Giai đoạn T3 chiếm $61,8 \%$, T4 chiếm 29,1\%. Sau điều trị chu vì u giảm chiếm $70,9 \%$. Tỉ lệ hạ thấp giai đoạn $64,1 \%$. 